\title{
A SOCIOLOGIA DE OCTAVIO IANNI
}

\author{
IANNI, Octavio \\ A Sociologia e o Mundo Moderno. \\ Rio de Janeiro: Civilização Brasileira, 2011, 399 p.
}

POR

\section{Maria Ribeiro do Valle}

$\mathrm{P}$ artindo da premissa de que o pensamento sociológico e a sociedade moderna são contemporâneos, Octavio Ianni em seu livro intitulado A Sociologia e o Mundo da sociologia desde os legados dos séculos que antecedem a sua emergência, em meados do século XIX, até os seus desdobramentos nos séculos seguintes.

Ianni mostra que a sociologia, diante da originalidade dos fatos da realidade social, que tem como principal símbolo o capital, com sua "missão civilizatória", não pode prescindir de suas raízes - os paradigmas das ciências físicas e naturais bem como do pensamento filosófico do século XVIII - e de suas polarizações que reverberam na (re)formulação dos princípios explicativos clássicos.

Longe de estabelecer uma continuidade linear sobre a história da sociologia, Ianni aponta para a complexidade e a peculiaridade das escolas que a inauguram, particularmente aquelas demarcadas pela "causação funcional" tendo Emile Durkheim como seu expoente; pela "conexão de sentido" com Max Weber e pela "contradição" com Karl Marx. Ianni elenca também uma gama significativa de autores controversos que na esteira dos clássicos revitalizam historicamente questões sociais candentes. Já aqui convida o leitor crítico a conhecer de perto as obras desses interlocutores, demarcando as suas filiações teóricas, as temáticas por eles revigoradas, as obras por eles

\footnotetext{
${ }^{1}$ Docente do Departamento de Sociologia da Faculdade de Ciências e Letras de Araraquara, Universidade Estadual Paulista "Júlio de Mesquita Filhos" - UNESP, Brasil. maria.ribeiro.valle@uol.com.br
} 
escritas, criando um "roteiro" instigante para aqueles que buscam abarcar a "autoconsciência científica da realidade social".

A questão social emerge, no horizonte da sociedade moderna, carregada de "laços que se rompem e incertos horizontes que se abrem" (p.21). Compreendê-la significa lançar luz às transformações e crises sociais decorrentes da dissolução da comunidade feudal e da emergência da sociedade capitalista sob diferentes matizes, quer no plano teórico, quer no plano político. Há, segundo Ianni, neste período, um misto de fascínio e espanto, pois ao mesmo tempo em que o progresso é enaltecido pela ciência, ele traz em si a transitoriedade histórica que aponta para futuros incertos. Irrompe um fervilhar de temas de envergadura social: tradição e modernidade; comunidade e sociedade; ordem e progresso; ideologia e utopia; revolução e contrarevolução. Eles ultrapassam as barreiras geográficas e permanecem na ordem do dia da agenda sociológica.

Para a compreensão da nova ordem social e seus desdobramentos, Octavio Ianni aborda, com rigor, a questão da metodologia nas ciências sociais percorrendo-a historicamente, ou seja, enaltecendo não apenas a contribuição das produções originais dos ensinamentos clássicos, como também a das novas teorias e paradigmas que mantêm com elas um fecundo diálogo na contemporaneidade. Considera esse debate fundamental por aflorar as controvérsias e aproximações dos diferentes autores, vertentes e escolas que se debruçam sobre as questões metodológicas - as quais ele identifica década após década - diante da compreensão da realidade social cada vez mais complexa e do inusitado desenvolvimento da Ciência e da Filosofia no século XX. É importante assinalar que ele não se refere aqui apenas ao "descortino da razão", mas também à sua "tirania" expressa no trágico desfecho das ilusões gestadas ao longo dos séculos XVIII e XIX devido ao nazismo, ao stalinismo e às guerras mundiais, que incidem diretamente na produção metodológica e social.

Estabelece também, a meu ver, duas importantes ressalvas quanto ao perigo das "tentações", quer de reduzir a sociologia à metodologia (e vice-versa), quer de cair na armadilha de, no afã pela novidade, característica marcante da contemporaneidade, desconsiderar o caráter acumulativo do conhecimento científico no terreno multidisciplinar da metodologia. Essa última atitude, para Octavio Ianni, acaba por demonstrar o desconhecimento de questões ontológicas e epistemológicas que já haviam sido formuladas anteriormente em horizontes mais fecundos, tornando inócuos os resultados das novas pesquisas. Aposta, assim, na direção positiva da "tentação" para a inovação metodológica, desde que desvencilhada das formulações a-históricas ou suprahistóricas que maculam o contínuo devir do real.

Octavio Ianni não se furta também ao debate sobre a "crise" da sociologia e de seus paradigmas que vem à tona desde o término da Segunda Guerra Mundial e durante 
a Guerra Fria, sendo muitas vezes entendida como a obsolescência das teorias clássicas. No entanto, sempre enfatizando a importância do momento do real, a sua historicidade, ele defende 0 contraponto entre 0 passado e o presente como essenciais para a compreensão de dada realidade social. Apesar de apresentar suas especificidades, os princípios explicativos das teorias sociais guardam fundamentos comuns como, por exemplo, a própria definição do social.

Ao mesmo tempo, a seu ver, a realidade social deve ser entendida como um "objeto em movimento", fato que implica na emergência de múltiplos paradigmas na contemporaneidade. Assim, a sociologia justamente por ser uma ciência peculiar que se pensa criticamente e requer, para tanto, uma "sociologia da sociologia" convive com "crises" de paradigmas em todo o seu desenrolar. Mas elas tomam vultos mais acentuados em determinados contextos históricos, como o novo "surto de globalização" do capitalismo, também concebido não apenas como modo de produção, mas como "processo civilizatório". Portanto, é importante não perder de vista as implicações políticas inerentes à pesquisa no campo das ciências sociais, diante das estruturas mundiais de poder econômico-político, dentre as quais se destaca a exercida pela mídia transnacional, que transforma o consumismo em exercício efetivo da cidadania e 0 cartão de crédito em carteira de identidade do indivíduo na "aldeia global".

A revolução burguesa em escala mundial, não apenas na Europa e nos Estados Unidos, mas também na América Latina, na África e na Ásia, gera paradoxalmente teorias que enaltecem o "deus" mercado e aquelas que a ele resistem porque insistem em revelar a ininterrupta desigualdade da apropriação na sociedade capitalista. 0 tema que merece maior destaque por Ianni nos seus escritos, portanto, é o desafio radical trazido pela globalização uma vez que "o novo mapa do mundo" requer novas metodologias e teorias para abranger de forma multidisciplinar as implicações geohistóricas, sociais, econômicas, políticas, culturais, demográficas, étnicas, religiosas, lingüísticas, ecológicas da inusitada realidade emergente.

Acredita, assim, que na passagem do século XX ao XXI "pode estar em curso não só uma ruptura histórica e uma ruptura epistemológica, mas uma revolução cultural de amplas proporções, na qual floresce uma revolução científica fundamental para as ciências sociais" (p.84). Contudo, adverte para o fato de que, quando elas se transformam em "técnicas sociais" mobilizadas pelas elites políticas e pelas classes dominantes que visam à manutenção do status quo, há uma reversão do sentido da ciência concebida como produto da "razão crítica". Ao subordinar-se à "razão instrumental", a própria ciência contribui para a perversão do sentido da atividade intelectual, impregnando as instituições universitárias, o ensino e a pesquisa reduzindoos ao utilitarismo, ao pragmatismo, à prioridade mercantil, às urgências das corporações transacionais e às estruturas mundiais de controle e apropriação, como resultado das implicações epistemológicas e ontológicas da industrialização da pesquisa 
científica. A ciência ao se metamorfosear em técnica social e política revela a "barbárie" que está presente não apenas em si mesma, mas na realidade social desde o século XIX, intensificando-se no século XX e invadindo crescentemente o século XXI.

Ou seja, a mesma racionalidade instrumental, que rege a sociedade, a economia, e a política, adquire ampla difusão na universidade, nas instituições de ensino e de pesquisa, explicitando o predomínio das teorias positivistas e neopositivistas que importam o paradigma que está na base da física e da matemática, ou seja, o das ciências naturais que têm por objetivo a apreensão do "como" dos fatos, procurando conhecer apenas as suas manifestações empiricamente observáveis para classificação e análise (cf. p.115). Concomitantemente há o desprestígio das teorias dialéticas que se ocupam com o "por que" e o "como" dos fatos, garantindo a reflexão crítica sobre 0 real, por conceber a sociedade ao mesmo tempo como objeto e sujeito do processo do conhecimento.

Seria um grande equívoco pensar que Octavio Ianni não considera a importância das ciências naturais para a elucidação das ciências sociais. Ao contrário, o que ele critica com veemência é quando elas se tornam hegemônicas e dissociadas das Humanidades. Tanto que ele se posiciona contrariamente não apenas a uma demarcação radical entre filosofia, ciências naturais, ciências sociais e artes, como também à exclusão da religião, dentre outras modalidades de vida cultural e intelectual por serem elas constitutivas da compreensão da realidade. Tal fato redunda na especialização, na "burocratização do pensamento", e no "desencantamento do mundo", comprometendo a "imaginação" e a reflexão dos cientistas que passam a exprimir o abandono do ponto de vista histórico pelas ciências sociais - a chamada "dissolução da história".

Em contrapartida há que se enfatizar que a história é uma dimensão da sociedade, exprimindo suas contradições e tensões, ou seja, a análise sociológica sempre se depara com a historicidade de seu objeto. Sendo assim, Octavio Ianni ainda aposta no fato de que a historicização das epistemologias, presente ainda em algumas escolas que resistem ao caráter de técnica de dominação da ciência, pode ser um caminho no sentido de repor a razão na estrada do realismo social (p.126).

Em suma, o livro de Ianni é emblemático de sua própria leitura da sociologia. Ele não descarta a importância das diversas abordagens clássicas e contemporâneas para a compreensão da realidade social bem como a da tematização dos enigmas da sociologia nas obras de diferentes cientistas, filósofos e artistas. Na contracorrente de uma visão reducionista da sociologia, ele lança mão de suas dimensões sociais e teóricas básicas, que não podem estar desconectadas das demais ciências como a antropologia, a ciência política, a geografia, a história, a economia. Essa abrangente concepção da sociologia do autor fundamenta a sua aposta em "refazer a esperança e a utopia", em 
suma, em "reinventar a vida". Dessa forma, deixa como legado uma forma instigante de enfrentar criticamente os desafios da "realidade social viva, complexa, intrincada, contraditória, em contínuo devir".

Acredito que em meados do século XIX a dissolução da comunidade feudal e a emergência da sociedade capitalista engendram a revolução do real clamando por uma nova ciência, a sociologia, capaz de desvendar seus enigmas. No contexto atual, a nova "revolução" que ocorre devido às transformações sociais de amplas proporções decorrentes da globalização, provocando inclusive uma ruptura histórica, não requer, contudo, a criação de uma ciência outra. A sociologia, por todo o seu conhecimento acumulado, continua podendo e devendo ser a sua interlocutora privilegiada desde que acompanhe o novo movimento real e virtual de seu objeto e reitere 0 seu papel de sujeito histórico. A Sociologia e o Mundo Moderno, obra póstuma de Octavio Ianni, é publicada por seus organizadores Antonio Ianni Segatto e José Antonio Segatto que presenteiam os cientistas sociais comprometidos com a compreensão da realidade no novo contexto do globalismo, no qual é preciso resistir não apenas à burocratização da realidade social como à pasteurização da pesquisa científica. A Sociologia e o Mundo Moderno passa a ser uma aliada da maior importância para aqueles que, além da compreensão da "sociedade global", vislumbram o reencantamento do mundo acalentado pela utopia. 